\title{
Integrating geochemical and reservoir engineering approach to evaluate reservoir continuity: A case study from Foroozan field, Offshore Iran
}

\author{
P Hassanzadeh ${ }^{1}$, A Hezarkhani ${ }^{2}$, , A R Rabbani ${ }^{1}$ and S Khajooie ${ }^{3}$ \\ ${ }^{1}$ Department of Petroleum Engineering, Amirkabir University of Technology, Hafez Ave. No. 424, Tehran, Iran. \\ ${ }^{2}$ Department of Mining and Metallurgy Engineering, Amirkabir University of Technology, Hafez Ave. No. 424, \\ Tehran, Iran. \\ ${ }^{3}$ Reservoir Engineering Department, National Iranian Oil Company-Exploration Directorate (NIOC-EXP), \\ Tehran, Iran. \\ *Corresponding author.e-mail: ardehez@aut.ac.ir
}

MS received 21 April 2018; revised 5 August 2018; accepted 21 August 2018; published online 22 March 2019

Foroozan field, with seven different reservoir layers, is one of the complex fields in the Persian Gulf. The purpose of this study was to identify intra-reservoir compartmentalisation using geochemical and reservoir engineering evidences. On the basis of this approach, 11 gaseous samples, which belong to different wells producing from the Burgan reservoir of Foroozan field, were selected. Gas composition, gas isotopes and associated oil bulk properties were tested to determine the reservoir continuity through the Burgan reservoir. In addition, fluid contacts and properties are also used to investigate reservoir continuity. Regarding clear differences in gas composition such as hydrogen sulphide concentrations, at least two separate segments in the north and south of the reservoir were detected. Moreover, the percentages of the different gas components indicated two separate compartments. Other evidences such as $\mathrm{C}_{1}-\mathrm{C}_{4}$ alkane isotopic compositions and sulphur and nitrogen isotopic signatures confirmed the Burgan reservoir compartmentalisation. A number of petroleum bulk properties confirmed gradual variations that provide supplementary evidence on the reservoir-filling direction, signifying that fluids equilibrium had not been extended through the Burgan reservoir, laterally. Initial reservoir condition, different original water-oil contacts, solution gas-oil ratio at original pressure and bubble point pressure are other reservoir engineering evidences that support the Burgan reservoir compartmentalisation.

Keywords. Foroozan oil field; Persian Gulf; Burgan reservoir; reservoir geochemistry; reservoir continuity; reservoir engineering.

\section{Introduction}

Typically, oils from continuous reservoir have the same hydrocarbon composition, whereas oils in compartmentalised reservoir almost always have significant differences with each other (Kaufman et al. 1990; England et al. 1995). Identifying the continuity or discontinuity of the reservoir can greatly help the reservoir engineers in determining the production behaviour of the reservoir, production allocation and prediction of gravitational gradients (England 2007). 
In several papers, various methods have been used to evaluate reservoir continuity such as formation of water analysis (Gill et al. 2010), geochemical fingerprinting (Kaufman et al. 1990; Hwang and Baskin 1994; Smalley and Hale 1996), gas geochemistry (Beeunas et al. 1999; Levachéet et al. 2000; Márquez et al. 2013), structural and stratigraphic continuity (Hovadik and Larue 2010), Fourier transform infra red (FTIR) and synchronous ultra violet fluorescence (SUVF) spectroscopy (Permanyer et al. 2002, 2007) and formation pressure measurements (Páez et al. 2010). However, in the recent years, the assessment of reservoir continuity using integrating geochemical and reservoir engineering approach has not been well documented.

Although few available studies utilise the whole range of parameters (proportions of each components and isotopic signatures), identifying reservoir compartmentalisation based on gas data has proven to be useful for further understanding of fluid heterogeneities within the reservoir (Rein and Schulz 2007).

Given the above considerations, the current study integrated geochemical and reservoir engineering data with the goal of clarifying the lateral continuity in the Burgan reservoir of Foroozan oil field (Persian Gulf). Regarding this goal, this is the first attempt in the Iranian hydrocarbon fields to assess the lateral reservoir continuity using gas geochemistry, bulk petroleum properties and reservoir fluid properties. In this paper, the gas composition of $\mathrm{C}_{1}-\mathrm{C}_{4}$ alkanes, carbon dioxide and molecular nitrogen together with isotopic signatures of each gas components has been used to define reservoir compartmentalisation. In addition, the API gravity, percentage of sulphide hydrogen and $\mathrm{V} / \mathrm{Ni}$ ratios in the associated oil samples are also provided to compare with the gas data.

\section{General geology of the field}

The Foroozan field was discovered in 1961 and is located in Persian Gulf about $100 \mathrm{~km}$ southwest of the Kharg Island (figure 1a). The Iranian portion of the field is named Foroozan, whereas the Saudi Arabian part of the field is known as Marjan. The Foroozan field is usually known for its specific complexities, and defining reservoir filling history for such a complex field is really perplexing. Structural and stratigraphic barriers separated the Foroozan field into five different sectors (F1,

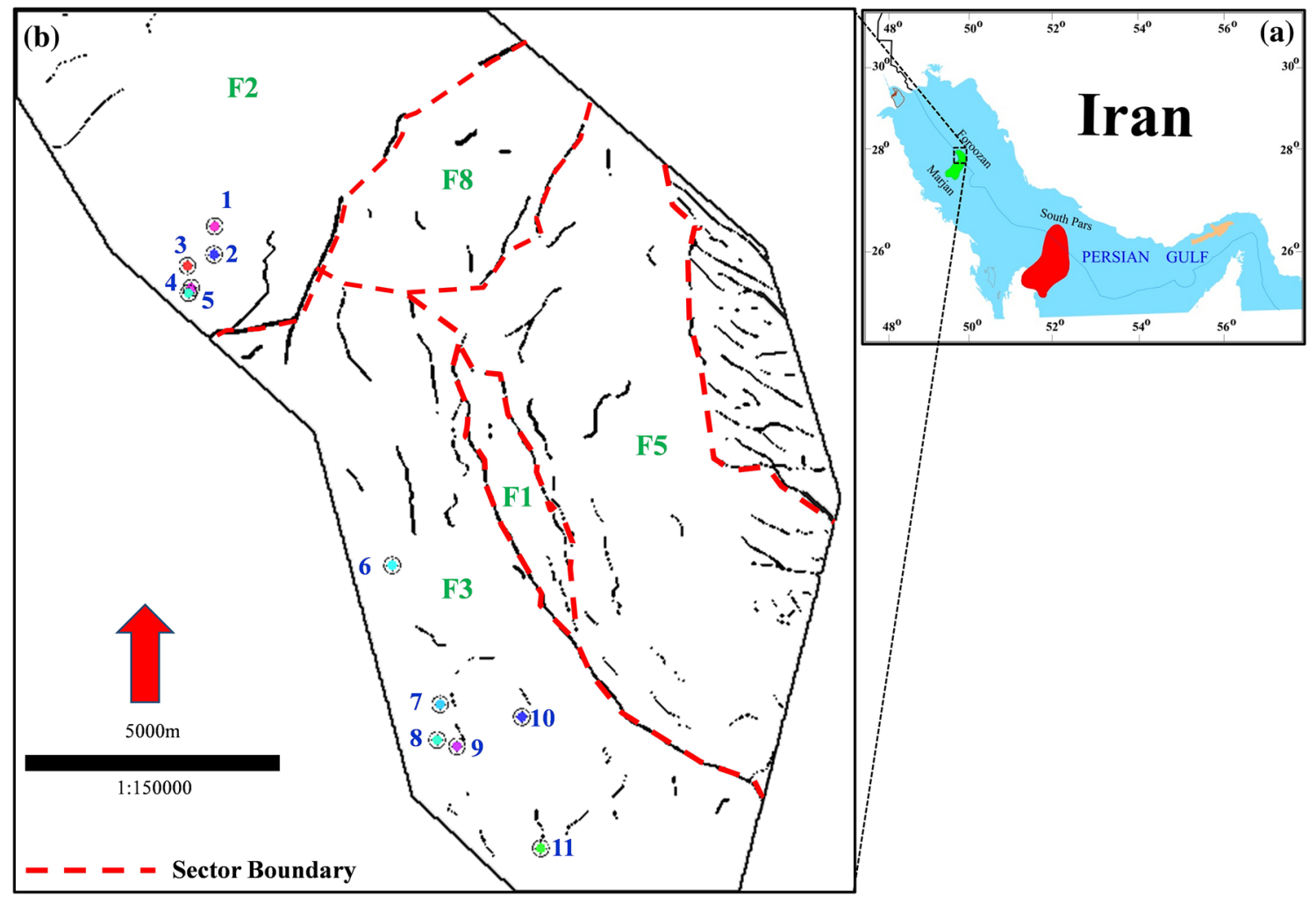

Figure 1. (a) Map of the Foroozan field in the Persian Gulf, Iran, and (b) sample locations with respect to fault distributions in the field. 
F2, F3, F5 and F8) (figure 1b) that are produced from seven different reservoirs. Heterogeneities of rock properties are detected throughout the field. Shale layers are present in two clastic formations, whereas the remaining five carbonate reservoirs are characterised by fractures and facies variations. Moreover, fluid properties vary laterally and vertically in the Burgan reservoir of the field. Most reservoirs in the field are producing under a combination of natural drive mechanisms (gas cap, solution gas and aquifer influx). The inadequate number of trustworthy pressure measurements in the Foroozan field makes stronger the uncertainties caused by the effect of the Marjan field (danaenergy.ir).

The primary reservoir in the Foroozan field is formed of fluvio-deltaic sandstones of the Albian the Lower Kazhdumi (Burgan Mbrs.). The Lower Kazhdumi (Burgan Mbrs.) in the Foroozan field is divided into a lower massive sandstone unit designated as Burgan-B and an upper shalier unit designated as Burgan-A (figure 2).

Additional reservoirs in the Foroozan field include carbonates of the Lower Cretaceous Dariyan (Shuaiba) and Fahliyan (Yammama), and the Upper Jurassic Manifa Mbr. and Surmeh (Arab Mbrs.) (figure 2).

\section{Samples and methods}

Eleven natural gas samples from 11 wells were collected in IsoTube instruments by means of a pressure regulator connected to a surface separator in the well-head. Surface separator pressures change between 430 and 670 psig in different wells. All of the sampled producing wells are from the Burgan reservoir. The reservoir is indicated as a saturated oil reservoir and is producing in the oil zone. Figure 1(b) shows the sampled wells in the field.

\subsection{Gas composition analysis}

The gas samples were analysed for their hydrocarbon composition from $\mathrm{C}_{1}-\mathrm{C}_{6}$ by GC-FID with a capillary PORAPLOT $\mathrm{N}$ column and for their permanent gas composition $\left(\mathrm{H}_{2} \mathrm{~S}, \mathrm{~N}_{2}, \mathrm{O}_{2}, \mathrm{CO}_{2}, \mathrm{CO}\right.$, $\mathrm{H}_{2}$ and $\mathrm{He}$ ) by GC-TCD (capillary MOLSIEVE and PORAPLOT N column) on a Shimadzu GC-2014 machine. The different compounds are determined by their retention times, and the

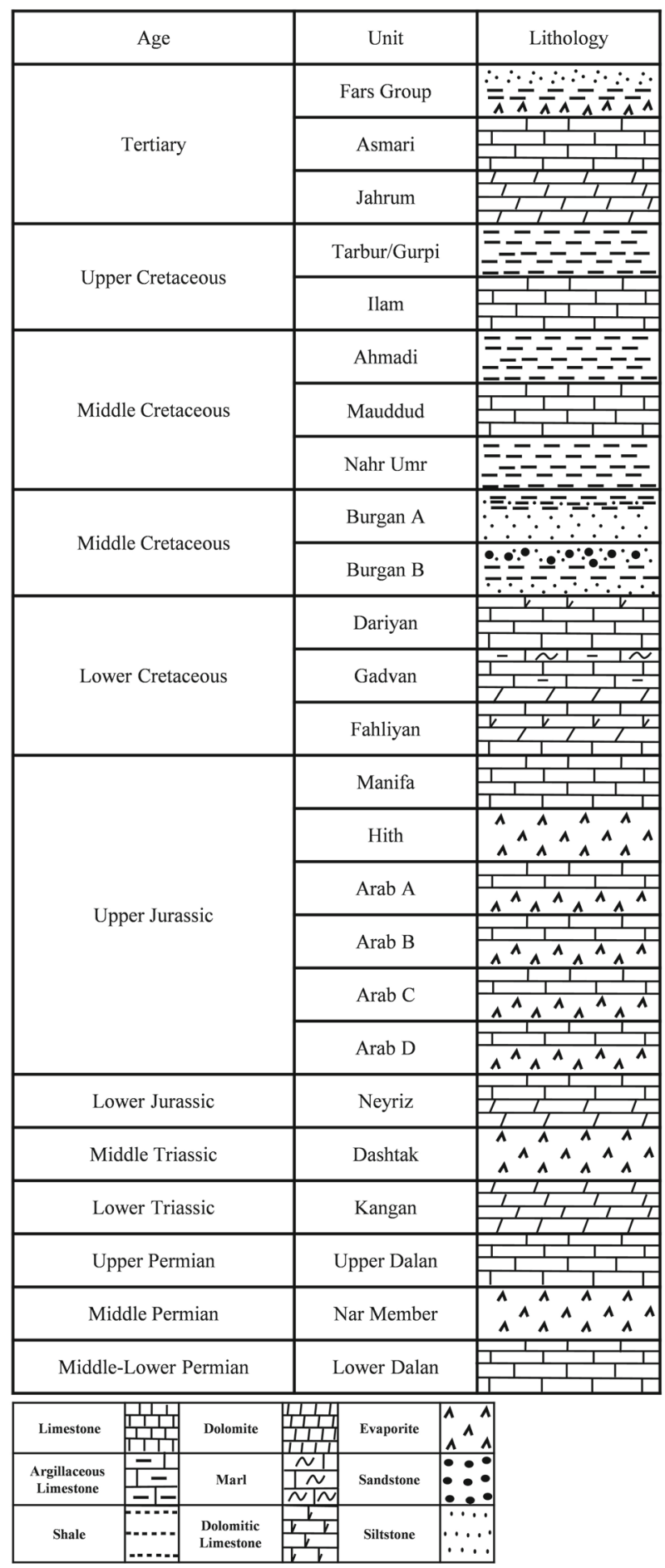

Figure 2. Simplified stratigraphy and lithological indexing of Foroozan field, Offshore Iran.

amounts of the compounds in the sample are proportional to the areas under the peaks. The measurement of uncertainty for the determination of gas compounds depends on the value and is in the range of $5-10$ relative $\%$. 
3.2 Continuous flow isotope ratio analysis (CF-IRMS ) ${ }^{13} \mathrm{C} /{ }^{12} \mathrm{C},{ }^{15} \mathrm{~N} /{ }^{14} \mathrm{~N}$ and $\mathrm{D} / \mathrm{H}$

${ }^{13} \mathrm{C} /{ }^{12} \mathrm{C},{ }^{15} \mathrm{~N} /{ }^{14} \mathrm{~N}$ and $\mathrm{D} / \mathrm{H}$ isotope analyses were performed by a CF-IRMS, PDZ EUROPA 2020. The gas chromatographic system used for all types of gas samples was a Hewlett-Packard HP 9890 Series II equipped with a 10-m long $16^{\prime \prime}$ SS-tube filled with Shin Carbon. The carrier gas was helium 6.0 and the temperature programme was set to $70^{\circ} \mathrm{C} /$ hold 5 min, rise $22^{\circ} \mathrm{C}$ per min $/ 320^{\circ} \mathrm{C}$ hold $20 \mathrm{~min}$. The uncertainty in the $\delta^{13} \mathrm{C}$ and $\delta^{15} \mathrm{~N}$ values was better than $\pm 0.3 \%$. The reproducibility of the $\delta \mathrm{D}$ values was approximately $\pm 2 \%$.

\section{$3.3 S$-34 isotope analysis by EA-IRMS}

The sulphur isotopic composition of gas samples was measured with a Flash HT 2000 elemental analyser (Thermo Scientific), equipped with combustion and pyrolysis furnaces, gas chromatograph capability and ion source of an IRMS Delta V Advantage (Thermo Scientific). Value of $\delta^{34} \mathrm{~S}$ for each sample was measured twice and the mean value was reported.

\subsection{Elemental composition (Ni, V)}

The Ni, V measurement was performed by applying the ICP-MS system. The ICP-MS system was assembled using a Metrohm 709 IC pump, a Metrosep ${ }^{\circledR}$ C4/4.0 $250 \mathrm{~mm}$ cation exchange column with a C4 GC/4.0 guard column and a PerkinElmer DRC e quadrupole ICP-MS with a quartz glass cyclone spray chamber combined with a Meinhard nebuliser.

\subsection{API measurement}

Applying ASTM D-4052 method (ASTM 2011), the API gravity of oil samples was measured.
A small volume $(\sim 0.7 \mathrm{ml})$ of oil sample was introduced into an oscillating sample tube and the change in oscillating frequency caused by the change in the mass of the tube was used in conjunction with the calibration data to determine the density of the sample.

\section{Results and discussion}

\subsection{Gas composition and isotopic signatures}

Molecular concentrations of different gas components including methane, ethane, propane, isobutane, $n$-butane, $n$-pentane, nitrogen, carbon dioxide and hydrogen sulphide are given in table 1 . The main constituent of the gas samples was methane, ranging between $53 \%$ and $89 \%$ (average $75.2 \%$ ).

The values of stable carbon isotopes of different components $\left(\mathrm{C}_{1}-\mathrm{C}_{5}\right.$ hydrocarbon and $\mathrm{CO}_{2}$ compounds), hydrogen signature of methane, ethane and propane, and the nitrogen isotopic composition for the gas samples are shown in table 2 . Regarding the $\delta^{13} \mathrm{C}$ and $\delta \mathrm{D}$ values of methane in different gases (Schoell 1980), a thermogenic origin for the studied samples can be considered (figure 3a). Similarly, according to Bernard diagram (figure $3 \mathrm{~b}$ ) wetness values higher than 0.23 and $\delta^{13} \mathrm{C}_{1}$ values over $-55 \%$ (except for well 5 ), the studied gas samples could be categorised as thermogenic gases (Berner and Faber 1988; Prinzhofer and Huc 1995). According to Schoell (1983), thermogenic origin of gas samples is also confirmed by the values of methane concentration and $\delta^{13} \mathrm{C}_{1}$ (figure $3 \mathrm{c}$ ). Moreover, using the model suggested by Chung et al. (1988), the 'natural gas plots' $\left(r^{2}>0.994\right.$ for wells $6-11$; see figure $3 \mathrm{~d}$ ) approve two groups of gases in the Burgan reservoir. In the first group, non-existent or limited biogenic methane fraction mixed with thermogenic

Table 1. Gas composition (molar percentage) from the Burgan reservoir gas samples, wells 1-11.

\begin{tabular}{llllllllllll}
\hline & 1 & 2 & 3 & 4 & 5 & 6 & 7 & 8 & 9 & 10 & 11 \\
\hline Methane & 71 & 72 & 53 & 73 & 57 & 89 & 84 & 81 & 84 & 80 & 84 \\
Ethane & 14 & 13 & 22 & 12 & 20 & 4.5 & 7.5 & 8.1 & 7.8 & 7.9 & 7.4 \\
Propane & 7.8 & 7.3 & 13 & 6.7 & 11 & 1.2 & 3 & 3.6 & 3.1 & 3.4 & 2.9 \\
$n$-Butane & 2.1 & 2.1 & 3.4 & 1.7 & 2.8 & 0.31 & 0.79 & 1.3 & 0.76 & 1 & 0.8 \\
i-Butane & 0.79 & 0.77 & 1 & 0.64 & 0.87 & 0.096 & 0.39 & 0.49 & 0.35 & 0.38 & 0.36 \\
$n$-Pentane & 0.55 & 0.6 & 1 & 0.42 & 0.7 & 0.19 & 0.17 & 0.53 & 0.14 & 0.35 & 0.2 \\
Nitrogen & 1.2 & 1.1 & 1.3 & 1.2 & 1.1 & 0.8 & 0.9 & 0.8 & 1 & 0.8 & 1 \\
Carbon dioxide & 0.9 & 0.9 & 3.2 & 0.8 & 3.4 & 0.6 & 0.3 & $<0.1$ & 0.2 & 3.4 & 0.5 \\
Hydrogen sulphide & $<0.05$ & $<0.05$ & 1.5 & $<0.05$ & 1.6 & $<0.05$ & $<0.05$ & $<0.05$ & $<0.05$ & 1.7 & $<0.05$ \\
\hline
\end{tabular}


Table 2. $\delta^{15} N$ and $\delta^{34} S$ data $(\%), \delta D(\%)$ and $\delta^{13} C$ values $(\%)$ in different gas components for the Burgan reservoir gas samples, wells 1-11.

\begin{tabular}{|c|c|c|c|c|c|c|c|c|c|c|c|}
\hline & 1 & 2 & 3 & 4 & 5 & 6 & 7 & 8 & 9 & 10 & 11 \\
\hline$\delta^{13} \mathrm{C}_{1}$ & -50.6 & -51.7 & -54.2 & -50.9 & -57.5 & -50.4 & -49.6 & -49.2 & -49.7 & -49.1 & -48.8 \\
\hline$\delta^{13} \mathrm{C}_{2}$ & -37.6 & -38.1 & -40.8 & -38.5 & -42 & -34.4 & -34.1 & -34.0 & -34.9 & -34.9 & -34.4 \\
\hline$\delta^{13} \mathrm{C}_{3}$ & -31.8 & -32.4 & -31.9 & -31.97 & -31.6 & -28.9 & -28.9 & -28.6 & -29.3 & -29.7 & -29.1 \\
\hline$\delta^{13} \mathrm{iC}_{4}$ & -30.6 & -28.6 & -32.7 & -30.4 & -31.4 & -28.7 & -28.4 & -28.2 & -30.4 & -31.5 & -28.7 \\
\hline$\delta^{13} n \mathrm{C}_{4}$ & -27.3 & -27.3 & -27.6 & -27.2 & -27.3 & -26.2 & -25.1 & -25.2 & -25.1 & -26.1 & -25.3 \\
\hline$\delta^{13} \mathrm{iC}_{5}$ & -23.7 & -22.5 & -24 & -23.4 & -24.3 & -23.4 & -23.4 & -23.5 & -22.8 & -23.5 & -23.6 \\
\hline$\delta^{13} n \mathrm{C}_{5}$ & -21.3 & -20.3 & -22 & -21.0 & -21 & -20.6 & -21.6 & -21 & -21.2 & -21.4 & -22.1 \\
\hline$\delta^{13} \mathrm{CO}_{2}$ & -8.3 & -10.4 & -4.8 & -9.3 & -2.9 & -5.3 & -4.6 & NI & -7.5 & -3.6 & -3.9 \\
\hline$\delta^{15} \mathrm{~N}$ & -2.8 & -1.1 & -4.2 & -2 & -5.3 & -2.5 & -1.7 & -1.8 & -3.3 & -5.8 & -3.2 \\
\hline$\delta \mathrm{DC}_{1}$ & -224 & -221 & -277 & -230 & -297 & -204 & -205 & -210 & -208 & -198 & -210 \\
\hline$\delta \mathrm{DC}_{2}$ & -144 & -122 & -140 & -129 & -133 & -94 & -115 & -113 & -118 & -100 & -122 \\
\hline$\delta \mathrm{DC}_{3}$ & -123 & -101 & -118 & -52 & -102 & -111 & -118 & -108 & -109 & -100 & -125 \\
\hline$\delta^{34} \mathrm{~S}$ & NI & NI & -2.4 & -11.9 & 4 & NI & $\mathrm{NI}$ & NI & NI & 10.7 & NI \\
\hline
\end{tabular}

Note: NI means not identified, below detection limit of instrument.
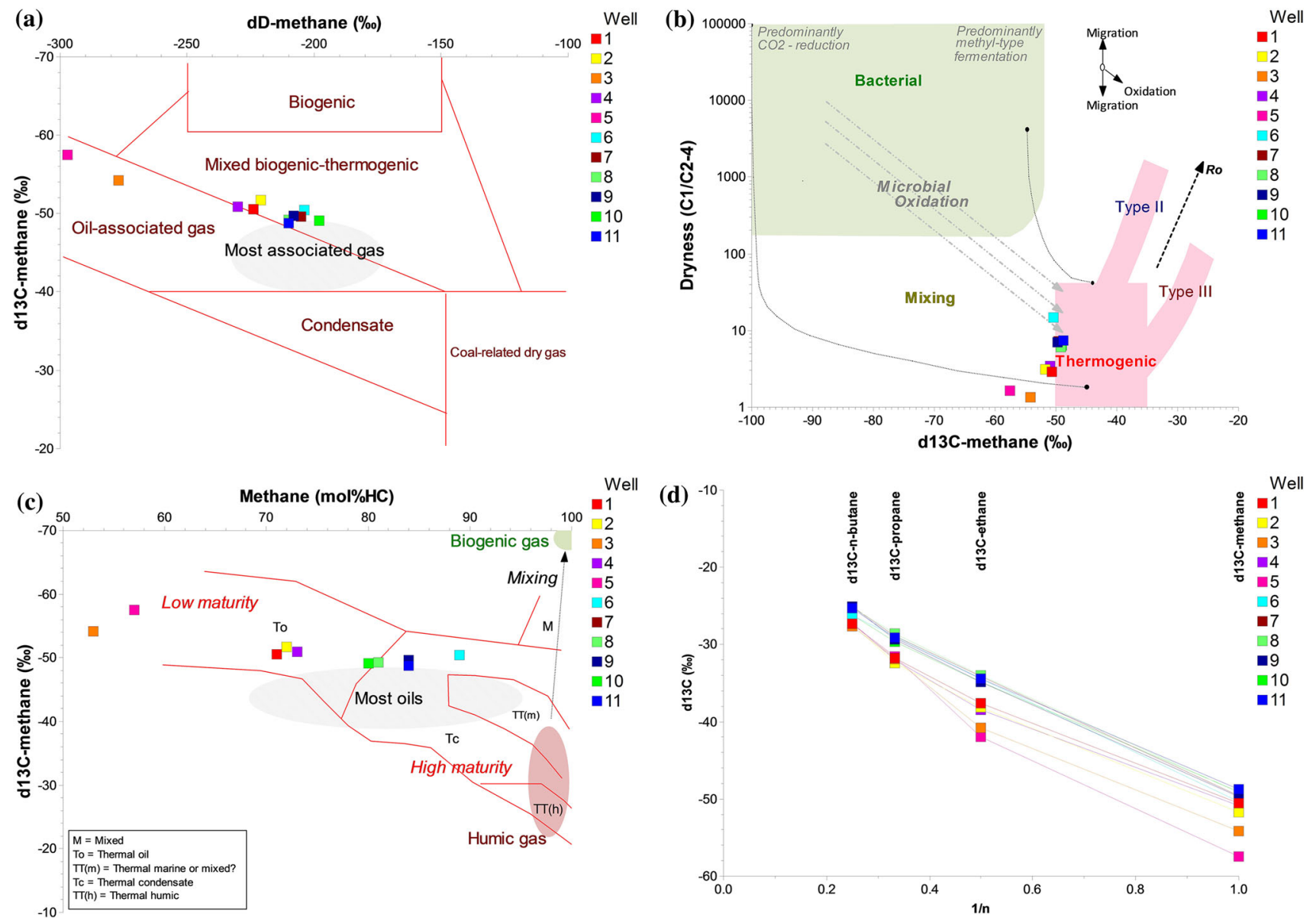

Figure 3. (a and b) Relationships of $\delta^{13} \mathrm{C}_{1}$ to $\mathrm{C}_{1} /\left(\mathrm{C}_{2}+\mathrm{C}_{3}+\mathrm{C}_{4}\right)$ and $\delta \mathrm{D}$ of methane to $\delta^{13} \mathrm{C}_{1}$ for the gas samples, respectively, and (c and $\mathbf{d}) \delta^{13} \mathrm{C}_{1}$ vs. methane concentration and $\delta^{13} \mathrm{C} v s$. the inverse $\mathrm{C}$ number of each $\mathrm{C}_{1}-\mathrm{C}_{4} n$-alkanes for two different groups of gas samples, respectively. 
one can be observed (Rangel et al. 2003). The second group comprises wells $1-5$, which are closely located to each other, and have lighter carbon isotopic composition of methane with respect to wells located in the southern part of the reservoir, about $3.5 \%$ in average. According to Chung et al. (1988), these values indicate methane leakage or diffusion in this part of the reservoir. The presence of different faults penetrating the Burgan reservoir is a possible proof of such a leakage in this part of the field. Moreover, a lower concentration of methane component in the area of these wells confirms the above-mentioned methane leakage or diffusion in this part of the Burgan reservoir.

A similar trend is observed based on the molar concentrations of the $\mathrm{C}_{1}-\mathrm{C}_{4}$ alkanes, with two notable exceptions. First of all, wells 3 and 5 show an unusually low value of methane concentration ( $57 \%$ and $53 \%$, respectively); in fact, in these two wells, the laboratory tests revealed a reservoir leakage in compliance with chemical analysis. Due to significantly lower concentration of methane, as the main compound, the relative concentration of other gas components will be changed. Beside these two wells, wells 1,2 and 4 show a higher concentration of methane (71-73\%) than the two other nearby wells. Nonetheless, these three wells have a lower methane concentration with respect to wells drilled in the southern part of the Burgan reservoir (80-89\%). It is completely in agreement with the isotopic signature of methane in the gas samples, $\sim 1.2-9.9 \%$ heavier in northern wells with respect to unaltered gas trend (figure $3 \mathrm{~d}$ ).

Valuable information could be provided from nitrogen concentrations in gas samples. Gases from wells $1-5$ presented molar nitrogen percentages (above 1.1\%) greater than those from the other wells (values between $0.8 \%$ and $1 \%$ ). The effect of geological baffles could be observed in molecular diffusion or convection based on this chemical dissimilarity.

There are some baffles between the wells of the northern part of the studied area. The nitrogen isotopic compositions of the gases from wells 3 and 5 are lighter than those from wells 1, 2 and 4 (about $2.5-4.2 \%$ ). Although all these five wells are quite close to each other, different isotopic and compositional signatures reveal lateral discontinuity in the reservoir to some extent.

Usually, methane shows an average lighter carbon isotopic ratio than ethane, whereas common Rayleigh 'fractionation' model (Clayton 1991) was observed based on the $\delta^{13} \mathrm{C}$ patterns of $\mathrm{C}_{1}-\mathrm{C}_{4}$ alkanes $\left(\mathrm{C}_{1}<\mathrm{C}_{2}<\mathrm{C}_{3}<\mathrm{C}_{4}\right)$ in the studied gas samples. The carbon isotopic compositions of methane from wells 1-5 presented differences of $3.52 \%$ compared to the other wells, in average (see table 2). Such an isotopic composition difference $(4.95 \%)$ was also observed in the ethane component of northern wells with respect to southern wells. These mentioned differences suggest special sealing features that prevent fluid equilibrium in the Burgan reservoir of Foroozan field. The gas correlation plot in figure 3 again demonstrates a clear difference in gas composition from the northern part with respect to mean values of the studied samples from the southern parts of the reservoir, which had low $\delta^{13} \mathrm{C}$ standard deviations $\left(<0.56^{0} \%\right)$. In contrast, $\delta^{13} \mathrm{C}$ for $\mathrm{C}_{1}-\mathrm{C}_{4} n$-alkanes in wells $1-5$ were completely lighter than other wells, showing that these wells belong to the same segment of the reservoir. These results confirm the chemical composition differences mentioned previously (methane and other components) between gas samples from the northern and southern parts of the reservoir and designate the occurrence of unconnected reservoir segments. Moreover, in the northern part of the reservoir, there is a clear discrimination between the samples from wells 3 and 5 with those from wells 1,2 and 4 based on the isotopic signature of methane, ethane and propane. The sulphur content of these wells also supports such a compartmentalisation in the northern part of the reservoir. Considering the sulphur content of the aforementioned gases, wells 3 and 5 have values in the range of $1.5-1.6 \% \mathrm{H}_{2} \mathrm{~S}$, whereas wells 1,2 and 4 have $<0.05 \%$ of $\mathrm{H}_{2} \mathrm{~S}$. The existence of some baffles between these closely located wells, which prevent complete fluid mixing, would be an explanation because there is no interpreted fault in the area of these five wells separating them from each other (figure 1b). In the wells located in the southern part of the reservoir (except well 10), the $\mathrm{H}_{2} \mathrm{~S}$ content of the gases is $<0.05 \%$, which indicates a complete reservoir segmentation within the field. Based on the $\mathrm{H}_{2} \mathrm{~S}$ content of the gas samples, some barriers in the reservoir prevent the mixing of well $10\left(\mathrm{H}_{2} \mathrm{~S}=1.7 \%\right)$ with adjacent wells in the Burgan reservoir in this part of the field.

Recent Burgan reservoir temperature in the Foroozan field varies from $80.6^{\circ} \mathrm{C}$ to $83.4^{\circ} \mathrm{C}$ in different wells. Modelling of burial history and petroleum generation in the Burgan reservoir of Foroozan field reveals that palaeotemperature did not exceed $100^{\circ} \mathrm{C}$. In general, Permo-Triassic reservoir is gas bearing in northwestern part of the 

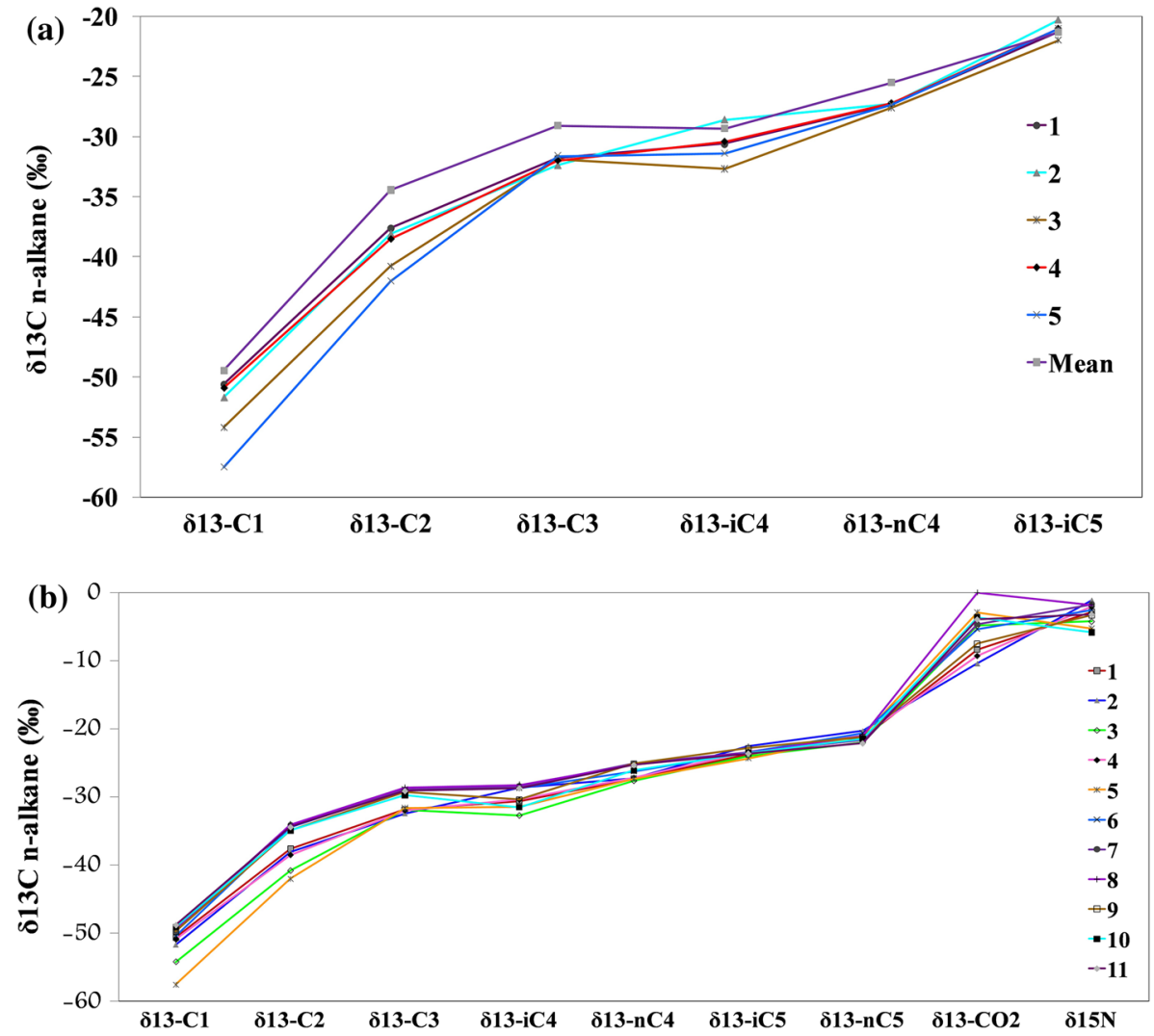

Figure 4. (a) $\delta^{13} \mathrm{C}$ values $(\%)$ in different gas components from wells 1 to 5 , and the mean of the remaining gas samples and (b) $\delta^{15} \mathrm{~N}$ data and $\delta^{13} \mathrm{C}$ values $(\%$ ) in different gas components for the Burgan reservoir sampled gases.

Persian Gulf. Similar modelling of Permo-Triassic reservoir in the Foroozan field indicates that the palaeotemperature achieved was more than $160^{\circ} \mathrm{C}$ and $140^{\circ} \mathrm{C}$ in Lower Dalan and Kangan reservoirs, respectively (Internal Report of NIOC-EXP 2017).

There are four gas samples containing $\mathrm{H}_{2} \mathrm{~S}$ content: two of them with positive values of $\delta^{34} \mathrm{~S}$ and others with negative values. Those with negative values of $\delta^{34} \mathrm{~S}$ (wells 3 and 4) indicate organic origin of $\mathrm{H}_{2} \mathrm{~S}$ in the analysed gas samples (from source rock kerogen decay). In wells 5 and 10, which have heavier sulphur isotope (4 and 10.7 respectively), gas migration from Permo-Triassic reservoir via faults conduit is an obvious process.

Thermochemical sulphate reduction is a thermally driven reaction leading to hydrocarbon oxidation with sulphate generating $\mathrm{H}_{2} \mathrm{~S}$ in hightemperature $\left(>100-140^{\circ} \mathrm{C}\right)$ geological and palaeogeographic settings (Machel 1998, 2001). During TSR reactions at first, ${ }^{32} \mathrm{~S}$ is produced as according to the required bond energy (Zhu et al. 2005), and the generated $\mathrm{H}_{2} \mathrm{~S}$ becomes progressively isotopically heavy as the process is continued. $\mathrm{CO}_{2}$ produced during TSR processes should be primarily depleted in ${ }^{13} \mathrm{C}$-isotope because it is derived from organic matter (e.g., Mougin et al. 2007; Zhang et al. 2008); however, as TSR continues, $\mathrm{CO}_{2}$ becomes successively enriched in ${ }^{13} \mathrm{C}$-isotope due to $\mathrm{CO}_{2}$ dissolution in water, and subsequent carbonate minerals precipitation could increase the $\delta^{13} \mathrm{C}$ of residual $\mathrm{CO}_{2}$ (Liu et al. 2014). A similar situation is in wells 5 and 10 , where isotopically heavy $\mathrm{CO}_{2}$ is found ( -2.9 and -3.6 , respectively), occurs in larger concentrations (3.2 and $3.4 \mathrm{vol} \%$, respectively) with respect to other studied gas samples (tables 1 and 2).

Although low $\mathrm{CO}_{2}$ and $\mathrm{H}_{2} \mathrm{~S}$ concentrations in the analysed gas samples are not typical of TSR because it leads to production of high concentrations of both these compounds, this fact does not exclude the occurrence of TSR processes in the geological history of the Permo-Triassic reservoir.

The coexistence of $\mathrm{CO}_{2}$ and $\mathrm{H}_{2} \mathrm{~S}$ in discussed gas samples indicates their common origin related mainly to TSR. Therefore, the presently occurring $\mathrm{H}_{2} \mathrm{~S}$ in the Burgan reservoir was most probably generated mainly during the past TSR process and kerogen decay (figure 4).

According to Whiticar et al. (1986) and Hill et al. (2007), isotopic data can also be used to investigate 


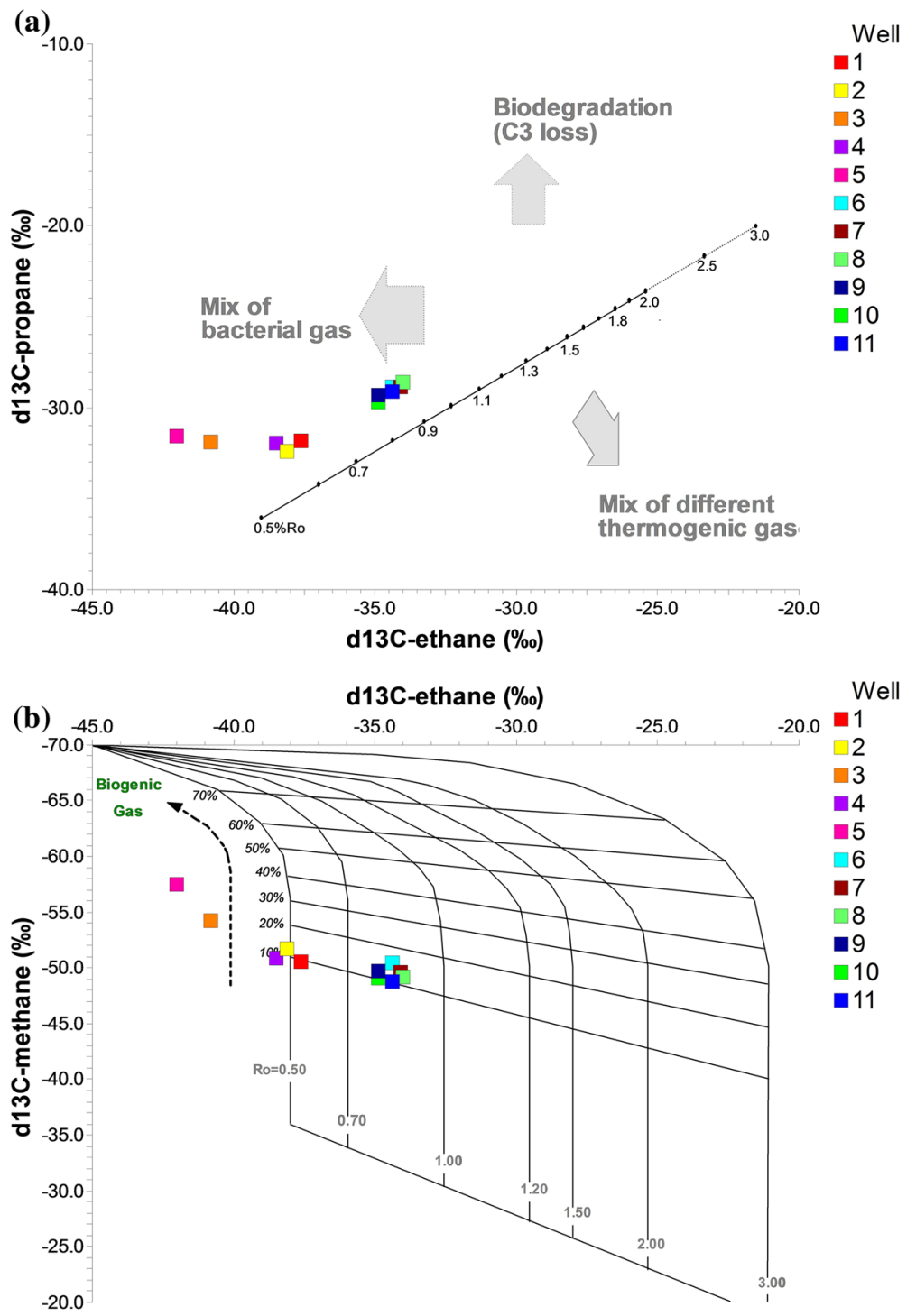

Figure 5. (a and b) Plot $\left(\delta^{13} \mathrm{C}_{3}\right.$ against $\left.\delta^{13} \mathrm{C}_{2}\right)$ and $\left(\delta^{13} \mathrm{C}_{1}\right.$ vs. $\left.\delta^{13} \mathrm{C}_{2}\right)$ for the Burgan reservoir gas samples.

about maturity levels of the gas samples. Actually, even though all the studied gas samples are in the range of oil window (see figure 5a and b, Vitrinite reflectance values below $1 \%$ ), heavier $\delta^{13} \mathrm{C}$ values for wells 6-11 may be due to an increase in the source rock maturity levels. Applying the scheme of Prinzhofer et al. (2000), biodegradation or secondary cracking in the Burgan reservoir can be rejected, as indicated by the low $\mathrm{C}_{2} / \mathrm{C}_{3}$ and $\mathrm{C}_{2} / \mathrm{iC}_{4}$ ratios in studied gas samples. Most of the samples are in the range of $\mathrm{C}_{2} / \mathrm{C}_{3}<3$ and $\mathrm{C}_{2} / \mathrm{iC}_{4}<30$; only one sample (well 6 ) exceeds the normal range of sample sets which is not within the secondary cracking or biodegradation interval values.

Segregative migration, accumulation efficiency and maturity are the main physicochemical processes affecting the isotopic signatures and chemical compositions of the gases (Prinzhofer et al. 2000). We applied gas data to star diagrams (also known as Gastar diagrams) to study these mentioned processes. According to Prinzhofer et al. (2000), 11 chemical and isotopic ratios $\left(\mathrm{C}_{1} / \mathrm{C}_{2}\right.$, $\mathrm{C}_{2} / \mathrm{C}_{3}, \quad \mathrm{iC}_{4} / n \mathrm{C}_{4}, \quad d^{13} \mathrm{C}_{1}, \quad d^{13} \mathrm{C}_{2}, \quad \delta^{13} \mathrm{C}_{3}, \quad \delta^{13} \mathrm{iC}_{4}$, $\delta^{13} n \mathrm{C}_{4}, \delta^{13} \mathrm{C}_{3}-\delta^{13} \mathrm{C}_{2}, \delta^{13} n \mathrm{C}_{4}-\delta^{13} \mathrm{iC}_{4}$ and $\delta^{13} \mathrm{C}_{2}-$ $\delta^{13} \mathrm{C}_{1}$ ) were investigated. All of these parameters are linked positively with maturity, 3 of the 11 defined parameters, $\delta^{13} \mathrm{C}_{3}-\delta^{13} \mathrm{C}_{2}, \delta^{13} n \mathrm{C}_{4}-\delta^{13} \mathrm{iC}_{4}$ and $\delta^{13} \mathrm{C}_{2}-\delta^{13} \mathrm{C}_{1}$, are considered as positively correlated with the efficiency of accumulation, and segregative migration may strongly affect the parameters involving methane $\left(\mathrm{C}_{1} / \mathrm{C}_{2}, d^{13} \mathrm{C}_{1}\right.$ and $\left.\delta^{13} \mathrm{C}_{2}-\delta^{13} \mathrm{C}_{1}\right)$. Figure 6 shows the 11 previously 

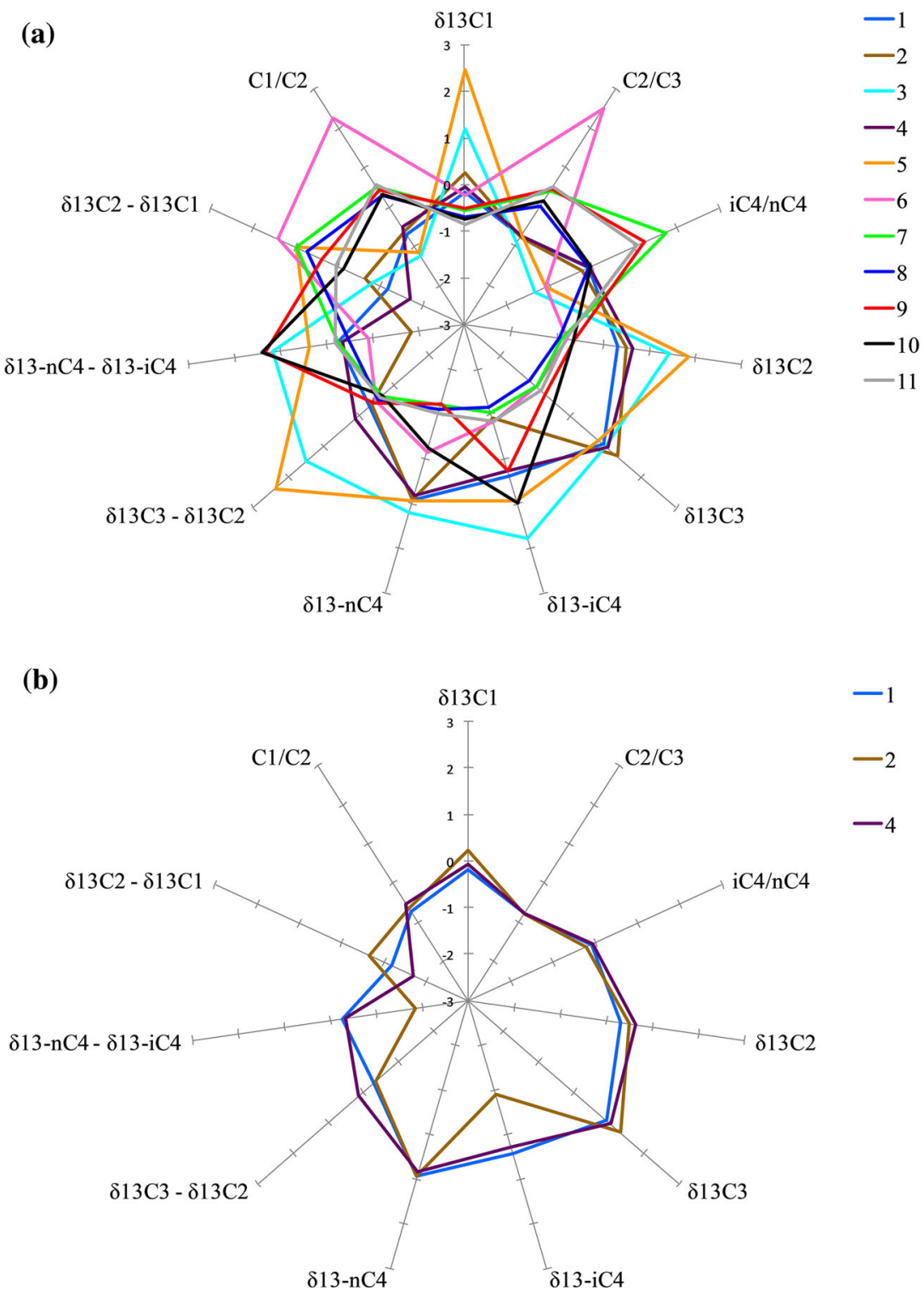

Figure 6. (a, b, c and $\mathbf{d})$ Normalised Gastar diagrams for different gas samples, Burgan reservoir. The scales are the same for all 11 axes of each Gaster diagram.

mentioned parameters plotted in four star diagrams. Figure 6a reveals obvious non-consistency of different gas samples regarding segregative migration, accumulation efficiency or maturity parameters. As expected, wells 1, 2 and 4 are in the same group, indicating the lowest degree of maturity (figure 6b). In comparison, Figure 6(c) shows the remaining samples (wells 1,2 and 4) from the northern part of the reservoir and demonstrates different behaviours; first of all, the accumulation efficiency is lowest among all sample sets. Results for these three samples show more maturity than two other samples in the northern part of the reservoir; but, this attribute is not sufficient to specify a new distinct reservoir segment. As a result, it cannot impede that the fluid heterogeneities recognised in star diagrams are signs of baffles that prevent complete mixing within the northern part of the reservoir.

Furthermore, the existence of differences in various geochemical parameters from studied gas samples reinforces the theory of at least two separate reservoir compartments in the Burgan reservoir of Foroozan oil field. Figure 6(d) presents gas samples from the southern part of the Burgan reservoir (wells 6, 7, 8, 9, 10 and 11) with greatest degree of maturity, migration fractionations and accumulation efficiencies, as well as small differences in these three processes. Regarding $\mathrm{C}_{1}-\mathrm{C}_{4}$ hydrocarbon analyses of gas samples from the 
(c)
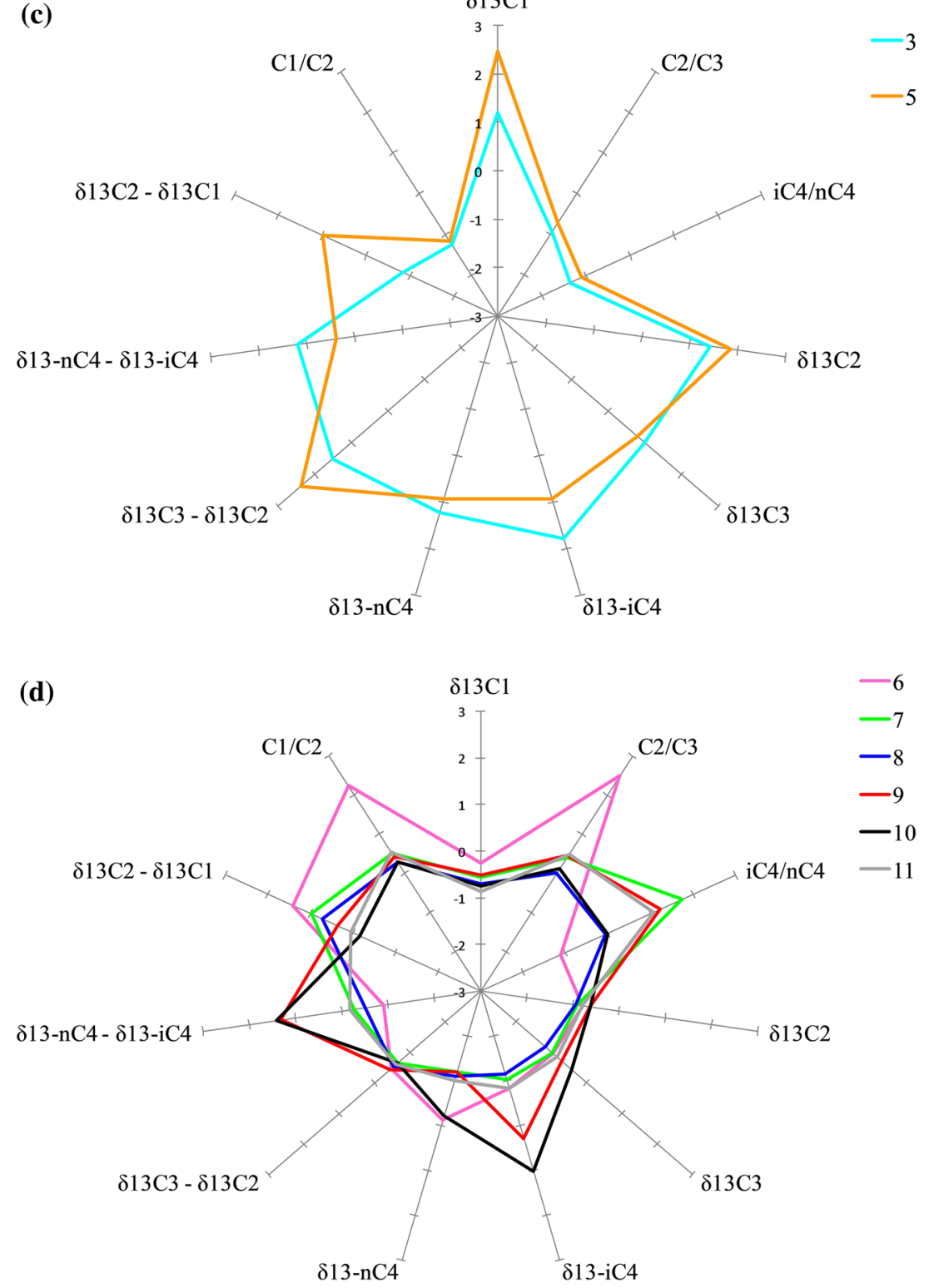

Figure 6. (Continued).

southern part of the Burgan reservoir, a reasonable continuity could be concluded, which indicate rather efficient convection mechanism for fluid mixing in the reservoir.

Comparing different sample sets in two different parts of the Burgan reservoir, more confined system is evident towards the southern part, and the efficiency of accumulation increases in this direction.

\subsection{Petroleum bulk properties}

$\mathrm{V} / \mathrm{Ni}$ ratios, API gravity, sulphur and asphaltene content of oil samples from the same wells as those from which gas samples were drawn (table 3 ) propose lateral heterogeneity in petroleum bulk properties. Unfortunately, the oil sample from well 5 of Foroozan field could not be taken because of operational problems.

Decreasing API values of sampled oils from south to north may be correlated with the northward decrease in maturity. Similarly, the increasing asphaltene content of crude oils in the same direction may be associated with the southward increase in maturity. Moreover, maturity increasing from north to south may illuminate the northward increase in the sulphur content of oils, which is probably related with higher concentrations of polar compounds (Moldowan et al. 2005). Especially, in samples from wells 7, 8 
Table 3. Petroleum bulk geochemical data, wells 1-11 except 5.

\begin{tabular}{lccccccccccc}
\hline & 1 & 2 & 3 & 4 & 6 & 7 & 8 & 9 & 10 \\
\hline $\mathrm{S}$ & 1.6 & 3.5 & 3.3 & 2.5 & 3.1 & 0.5 & 0.1 & 0.7 & 2.4 & 3.4 \\
$\mathrm{~V}$ & 41.6 & 60.7 & 109.4 & 65.8 & 45.7 & 0.7 & 0.98 & 0.2 & 11.7 & 68.2 \\
$\mathrm{Ni}$ & 13.4 & 30.7 & 38 & 20 & 28.5 & 0.99 & 0.99 & 0.99 & 4.9 & 21.6 \\
$\mathrm{~V} / \mathrm{Ni}$ & 3.1 & 1.98 & 2.88 & 3.29 & 1.6 & 0.71 & 0.99 & 0.2 & 2.39 & 3.16 \\
Asphaltene & 101 & 96 & 75 & 82 & 60 & 1 & 0 & 1 & 54 & 60 \\
API & 23.8 & 22 & 23.8 & 24.2 & 29 & 68.5 & 70.3 & 69.9 & 40.3 & 39.8 \\
\hline
\end{tabular}

Note: $\mathrm{S}$ in per cent, $\mathrm{V}$ and $\mathrm{Ni}$ in ppm and asphaltene in $\mathrm{mg}$.

Table 4. Burgan reservoir fluid properties in the Foroozan field.

\begin{tabular}{lll}
\hline Fluid properties & F2 area & F3 area \\
\hline Reservoir pressure @ 6700 ftss & 3310 & 3310 \\
Formation volume factor (FVF) at original pressure & 1.18 & 1.45 \\
$\quad($ BBL/STB) & & 272 \\
Solution gas-oil ratio at original pressure (SCF/BBL) & 3.6 & 830 \\
Oil viscosity at original pressure (cp) & 1330 & 0.8 \\
Bubble point pressure (psig) & Undersaturated & 3310 \\
Initial reservoir condition & 25.6 & Saturated \\
Specific gravity of residual oil (API) & & 29.4 \\
\hline
\end{tabular}

and 9, the asphaltene content and $\mathrm{S}$ percentage decrease dramatically, which is associated with more mature hydrocarbon charging in this part of the reservoir. There is a general increase of $\mathrm{V}$, $\mathrm{Ni}$ and $\mathrm{V} / \mathrm{Ni}$ ratio northward. The lowest concentration of $\mathrm{V}, \mathrm{Ni}$ and $\mathrm{V} / \mathrm{Ni}$ ratio is in wells 7,8 and 9 in the southern part of the reservoir. $\mathrm{V} / \mathrm{Ni}$ ratio more than 3 and concentrations generally lower than $90 \mathrm{ppm}$ propose carbonate shale and marine organic material or limestone as a source rock deposited in anoxic sedimentary environment (wells 1, 4 and 11 ). $\mathrm{V} / \mathrm{Ni}$ ratio ranging from 1.9 to 3 shows that the corresponding source rocks were deposited under dysoxic-oxic conditions with predecessor mixed origin organic matter: continental and, mainly, marine (wells $2,3$ and 10$) . \mathrm{V} / \mathrm{Ni}$ ratio lower than 1.9 indicates terrestrial organic materials, with predominant oxic conditions during the deposition of associated source rocks (wells 6, 7, 8 and 9) (Galarraga et al. 2008).

Therefore, the Burgan reservoir demonstrates obvious changes in composition from the northern to the southern part of the field. Based on the data discussed above, we suggest that the Burgan reservoir was charged from the south, it means that the source rock deposited in the southern part of the field. Low maturity oils accumulated in the northern section of the reservoir and subsequent petroleum expulsion from the source rock kitchen area accumulated in the southern part of the reservoir.

\subsection{Reservoir engineering evidences}

Geological barriers separated the Foroozan field into five different sectors (F1, F2, F3, F5 and F8). Wells $1-5$ are located in the F2 segment and other wells containing wells $6-11$ are in the F3 area. The separation concept is supported by several reservoir engineering evidences which will be described in the following paragraphs.

F2 and F3 sectors in the Burgan reservoir are separated based on the data obtained regarding fluid contacts and fluid properties. The original water-oil contacts (WOCs) used to define the individual reservoir productive limits are -6845 and -6855 ftss (feet subsea) in F2 and F3 segments, respectively. Different original WOCs in the F2 and F3 areas indicate that the Burgan reservoir is separated and probably not in communication with each other in these two areas.

The Burgan reservoir compartmentalisation is also supported by different reservoir fluid properties for Burgan in F2 and F3 areas (table 4). Based on the laboratory results of eight bottom hole samples (BHS) taken from the Burgan reservoir, it is indicated that the Burgan reservoir in the F2 area is highly saturated with a 

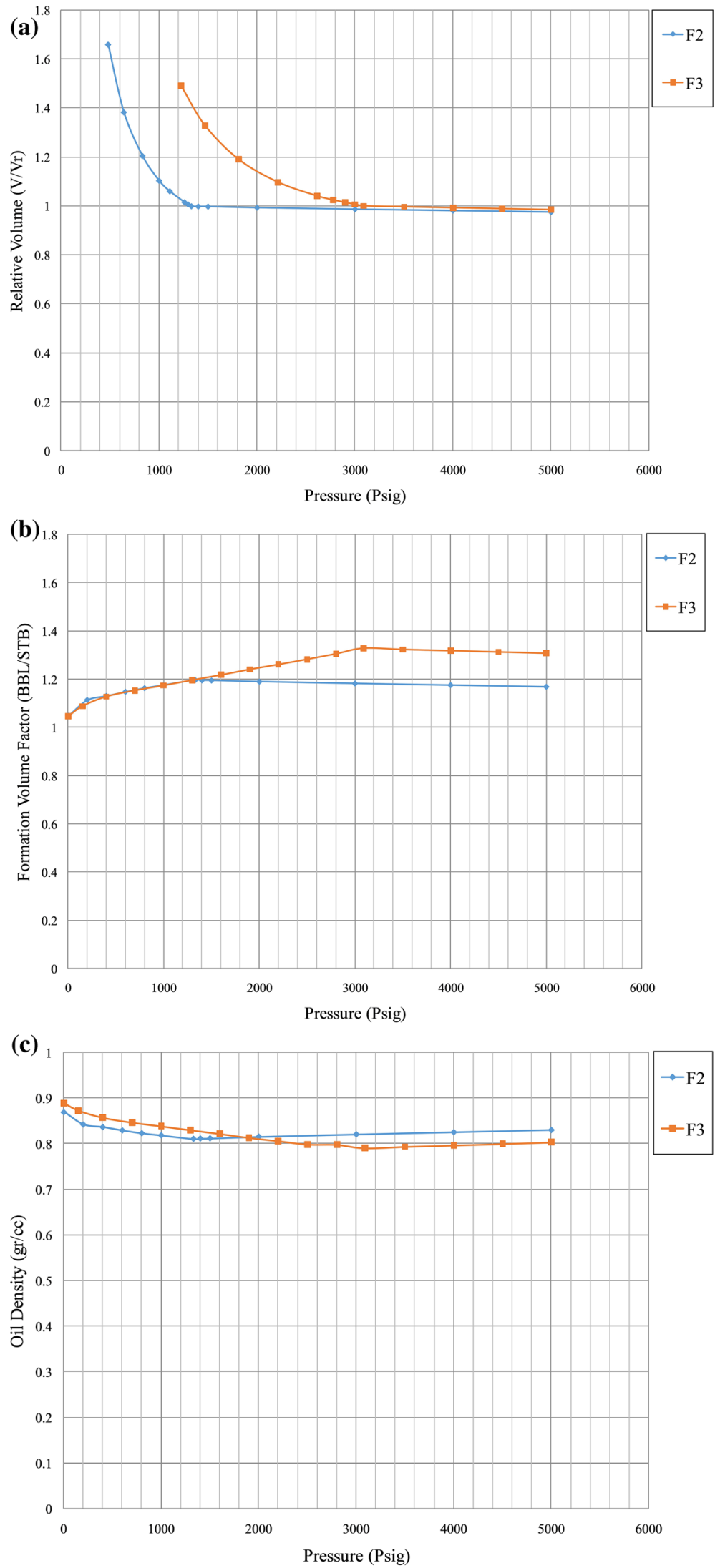

Figure 7. (a, b, c and $\mathbf{d})$ Relative volume, formation volume factor, solution gas-oil ratio and oil density $(d)$ of the Burgan reservoir fluid samples in F2 and F3 areas, Foroozan oil field. 


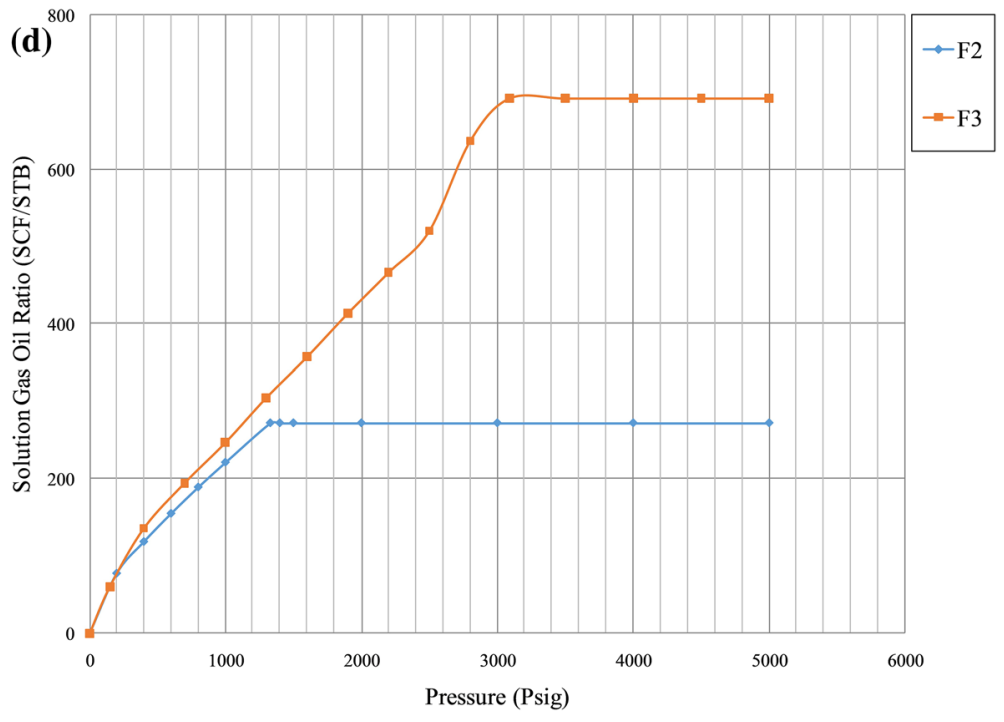

Figure 7. (Continued).

bubble point of approximately 1330 psig and a solution gas-oil ratio (GOR) at the bubble point of approximately $272 \mathrm{ft}^{3} / \mathrm{bbl}$ (cubic feet/barrel). This is further supported by the well test GOR data since the initial and historical well test GORs are well in line with bubble point solution GOR. The BHS solution GOR data and the initial well test GOR data indicate that the Burgan reservoir in the F3 area is probably initially saturated reservoir. The presence of an initial gas cap in the F3 area is also indicative of initial saturated conditions.

Table 4 compares the average fluid properties of the Burgan reservoir in F2 and F3 sectors, which clearly support the segmentation concept in the Burgan reservoir of Foroozan field.

The Burgan reservoir oil viscosity in the F2 area is approximately four times greater than oil viscosity in the F3 area, thereby indicating that this reservoir is clearly divided into two distinct parts. Another important property, which is different in F2 and F3 areas, is the reservoir fluid gravity (API). The values of specific gravity of residual oil (API) in F2 and F3 areas are 25.6 and 29.4, respectively.

Moreover, the comparison of laboratory results such as relative volume (figure $7 \mathrm{a}$ ), formation of volume factor (figure 7b), solution GOR (figure 7c) and oil density (figure $7 \mathrm{~d}$ ) of the Burgan reservoir fluid samples in F2 and F3 areas is shown in figure 7 . It is obvious that the reservoir fluids in these two areas are different which support the concept of the Burgan reservoir segmentation.

\section{Conclusions}

The compositional and isotopic signatures of each $\mathrm{C}_{1}-\mathrm{C}_{4}$ aliphatic hydrocarbons and $\mathrm{H}_{2} \mathrm{~S}$ contents in the studied gases suggest clear differences between the northern part of the reservoir and the remaining gas samples towards the south. Especially, the $\mathrm{H}_{2} \mathrm{~S}$ contents presented a prominent change between these two parts of the reservoir, thus proposing a sealing mechanism related to the fault recognised in the geological section. At least, two separate reservoir compartments were revealed in the Burgan reservoir of the Foroozan oil field.

On the basis of gas analysis results, the existence of baffles or barriers in the northern and southern parts of the reservoir is probable, as certain analytical patterns do not exclude a scenario of other separate segments. Detailed geological study and geochemical monitoring are necessary to pinpoint the additional minor flow baffles or barriers.

The API gravity, sulphur concentrations and $\mathrm{V} / \mathrm{Ni}$ ratio of the studied oils support a southnorth compositional change within the Burgan reservoir. Integrating all the geochemical parameters available, we conclude that this reservoir was charged from the south.

Reservoir engineering evidences including initial reservoir condition, different original WOCs, solution GOR at original pressure, bubble point pressure and oil viscosity at original pressure confirm the Burgan reservoir compartmentalisation. 


\section{Acknowledgements}

We are grateful to the National Iranian Oil Company-Exploration Directorate for granting us in this research. We also thank the Iranian Offshore Oil Company (IOOC) for accessing to the samples. The authors thank A Yahyaei from IOOC for his assistance. We also would like to thank the Institute of Geology and Geochemistry of Petroleum and Coal, RWTH Aachen University, GEO-data and Hydroisotop Companies for analysing the samples.

\section{References}

ASTM 2011 D-4052: Standard for density, relative density, and API gravity of liquids by digital density meter; American Society for Testing Materials Standards.

Beeunas M A, Baskin D K and Schoell M 1999 Application of gas geochemistry for reservoir continuity assessment and identification of fault seal breakdown, South Marsh Island 61, Gulf of Mexico; In: AAPG Hedberg research conference 'natural gas formation and occurrence', Durango, Colorado.

Berner U and Faber E 1988 Maturity related mixing model for methane, ethane and propane, based on carbon isotopes; Org. Geochem. 13(1-3) 67-72.

Chung H M, Gormly J R and Squires R M 1988 Origin of gaseous hydrocarbons in subsurface environments: Theoretical considerations of carbon isotope distribution; Chem. Geol. 71(1-3) 97-104.

Clayton C 1991 Carbon isotope fractionation during natural gas generation from kerogen; Mar. Pet. Geol. 8(2) 232240.

Dana Energy. https://www.danaenergy.ir/en/media-menu/ dana-magazine/projects/item/256-achievments-of-inte-gr ated-mdp-study-of-foroozan-field/.

England W A 2007 Reservoir geochemistry - A reservoir engineering perspective; J. Pet. Sci. Eng. 58(3-4) 344354.

England W A, Muggeridge A H, Clifford P J and Tang Z 1995 Modelling density-driven mixing rates in petroleum reservoirs on geological time-scales, with application to the detection of barriers in the forties field (UKCS); Geol. Soc. London, Spec. Publ. 86(1) 185-201.

Galarraga F, Reategui K, Martïnez A, Martínez M, Llamas J F and Márquez G $2008 \mathrm{~V} / \mathrm{Ni}$ ratio as a parameter in palaeoenvironmental characterisation of nonmature medium-crude oils from several Latin American basins; J. Pet. Sci. Eng. 61(1) 9-14.

Gill C E, Shepherd M and Millington J J 2010 Compartmentalization of the Nelson field, Central North Sea: Evidence from produced water chemistry analysis; Geol. Soc. London, Spec. Publ. 347(1) 71-87.

Hill R J, Jarvie D M, Zumberge J, Henry M and Pollastro R M 2007 Oil and gas geochemistry and petroleum systems of the Fort Worth Basin; AAPG Bull. 91(4) 445-473.
Hovadik J M and Larue D K 2010 Stratigraphic and structural connectivity; Geol. Soc. London, Spec. Publ. 347(1) 219-242.

Hwang R J and Baskin D K 1994 Reservoir connectivity and oil homogeneity in a large-scale reservoir; Geo $\mathbf{9 4}(\mathbf{2})$ 529-541.

Internal Report of NIOC Exploration Directorate 2017 Geological and geophysical studies carried out on Persian Gulf and Abadan Plateau of the Islamic Republic of Iran.

Kaufman R L, Ahmed A S and Elsinger R L 1990 Gas chromatography as a development and production tool for fingerprinting oils from individual reservoirs: Applications in the Gulf of Mexico; In: GCSSEPM foundation ninth annual research conference proceedings, 1 October, pp. 263-282.

Levachéet D, Montel F and Walgenwitz F 2000 Deep offshore fluid evaluation/connectivity study; In: SPE annual technical conference and exhibition, Society of Petroleum Engineers.

Liu Q, Jin Z, Wu X, Liu W, Gao B, Zhang D, Li J and Hu A 2014 Origin and carbon isotope fractionation of $\mathrm{CO}_{2}$ in marine sour gas reservoirs in the Eastern Sichuan Basin; Org. Geochem. 74 22-32.

Machel H G 1998 Gas souring by thermochemical sulfate reduction at $140^{\circ} \mathrm{C}$ : Discussion; AAPG Bull. $\mathbf{8 2 ( 1 0 )}$ 1870-1873.

Machel H G 2001 Bacterial and thermochemical sulfate reduction in diagenetic settings - Old and new insights; Sedim. Geol. 140(1-2) 143-175.

Márquez G, Escobar M, Lorenzo E, Gallego J R and Tocco R 2013 Using gas geochemistry to delineate structural compartments and assess petroleum reservoir-filling directions: A Venezuelan case study; J. S. Am. Earth Sci. 43 $1-7$.

Moldowan J M, Peters K E and Walters C C 2005 The Biomarker Guide: Biomarkers and Isotopes in Petroleum Systems and Earth History; Cambridge University Press, England.

Mougin P, Lamoureux-Var V, Bariteau A and Huc A Y 2007 Thermodynamic of thermochemical sulphate reduction; J. Pet. Sci. Eng. 58(3-4) 413-427.

Páez R H, Lawerence J J and Zhang M 2010 Compartmentalization or gravity segregation? Understanding and predicting characteristics of near-critical petroleum fluids; Geol. Soc. London, Spec. Publ. 347(1) 4353.

Permanyer A, Douifi L, Lahcini A, Lamontagne J and Kister J 2002 FTIR and SUVF spectroscopy applied to reservoir compartmentalization: A comparative study with gas chromatography fingerprints results; Fuel 81(7) 861866.

Permanyer A, Rebufa C and Kister J 2007 Reservoir compartmentalization assessment by using FTIR spectroscopy; J. Pet. Sci. Eng. 58(3-4) 464471.

Prinzhofer A A and Huc A Y 1995 Genetic and post-genetic molecular and isotopic fractionations in natural gases; Chem. Geol. 126(3-4) 281-290.

Prinzhofer A, Mello M R, da Silva Freitas L C and Takaki T 2000 Chapter 9: New geochemical characterization of natural gas and its use in oil and gas evaluation; $A A P G$ Memoir 73 107-119. 
Rangel A, Katz B, Ramirez V and dos Santos Neto E V 2003 Alternative interpretations as to the origin of the hydrocarbons of the Guajira Basin, Colombia; Mar. Pet. Geol. 20(2) 129-139.

Rein E and Schulz L K 2007 Applications of natural gas tracers in the detection of reservoir compartmentalisation and production monitoring; J. Pet. Sci. Eng. 58(3-4) 428442.

Schoell M 1980 The hydrogen and carbon isotopic composition of methane from natural gases of various origins; Geochim. Cosmochim. Acta 44(5) 649-661.

Schoell M 1983 Genetic characterization of natural gases; AAPG Bull. 67(12) 2225-2238.

Smalley P C and Hale N A 1996 Early identification of reservoir compartmentalization by combining a range of

Corresponding editor: PARTha Pratim Chakraborty conventional and novel data types; SPE Form. Eval. 11(03) 163-170.

Whiticar M J, Faber E and Schoell M 1986 Biogenic methane formation in marine and freshwater environments: $\mathrm{CO}_{2}$ reduction vs. acetate fermentation - isotope evidence; Geochim. Cosmochim. Acta 50(5) 693-709.

Zhang T, Amrani A, Ellis G S, Ma Q and Tang Y 2008 Experimental investigation on thermochemical sulfate reduction by $\mathrm{H}_{2} \mathrm{~S}$ initiation; Geochim. Cosmochim. Acta 72(14) 3518-3530.

Zhu G, Zhang S, Liang Y, Dai J and Li J 2005 Isotopic evidence of TSR origin for natural gas bearing high $\mathrm{H}_{2} \mathrm{~S}$ contents within the Feixianguan formation of the northeastern Sichuan Basin, southwestern China; Sci. China Ser. D. 48(11) 1960. 